\title{
Frailty in community-dwelling older adults: association with adverse outcomes
}

\author{
This article was published in the following Dove Press journal: \\ Clinical Interventions in Aging \\ 26 June 2017 \\ Number of times this article has been viewed
}

\author{
Sergio Sánchez-García' \\ Carmen García-Peña ${ }^{2}$ \\ Antoni Salvà ${ }^{3}$ \\ Rosalinda Sánchez-Arenas' \\ Víctor Granados-García' \\ Juan Cuadros-Moreno ${ }^{4}$ \\ Laura Bárbara Velázquez- \\ Olmedo 5 \\ Ángel Cárdenas-Bahena' \\ 'Epidemiology and Health Services \\ Research Unit, Aging Area, Centro \\ Médico Nacional Siglo XXI, Instituto \\ Mexicano del Seguro Social, ${ }^{2}$ Research \\ Department, Instituto Nacional de \\ Geriatría, Institutos Nacionales de \\ Salud de México, Secretaría de Salud, \\ ${ }^{3}$ Health and Ageing Foundation, \\ Universitat Autònoma de Barcelona, \\ Barcelona, España, ${ }^{4}$ Coordination of \\ Health Education, Instituto Mexicano \\ del Seguro Social, ${ }^{5}$ Department of \\ Public Health and Oral Epidemiology, \\ Facultad de Odontología, Universidad \\ Nacional Autónoma de México, \\ Ciudad de México, México
}

Background: The study of frailty is important to identify the additional needs of medical long-term care and prevent adverse outcomes in community dwelling older adults. This study aimed to determine the prevalence of frailty and its association with adverse outcomes in community dwelling older adults.

Methods: A cross-sectional study was carried out from April to September 2014. The population sample was 1,252 older adults ( $\geq 60$ years) who were beneficiaries of the Mexican Institute of Social Security (IMSS) in Mexico City. Data were derived from the database of the "Cohort of Obesity, Sarcopenia and Frailty of Older Mexican Adults" (COSFOMA). Operationalization of the phenotype of frailty was performed using the criteria of Fried et al (weight loss, self-report of exhaustion, low physical activity, slow gait, and weakness). Adverse outcomes studied were limitation in basic activities of daily living (ADLs), falls and admission to emergency services in the previous year, and low quality of life (WHOQOL-OLD).

Results: Frailty was identified in $20.6 \%(\mathrm{n}=258)$, pre-frailty in $57.6 \%(\mathrm{n}=721)$, and not frail in $21.8 \%(\mathrm{n}=273)$. The association between frailty and limitations in ADL was odds ratio $(\mathrm{OR})=2.3(95 \%$ confidence interval $[\mathrm{CI}] 1.7-3.2)$ and adjusted $\mathrm{OR}=1.7$ (95\% CI 1.2-2.4); falls $\mathrm{OR}=1.6(95 \%$ CI 1.2-2.1) and adjusted OR $=1.4$ (95\% CI 1.0-1.9); admission to emergency services $\mathrm{OR}=1.9(95 \% \mathrm{CI} 1.1-3.1)$ and adjusted $\mathrm{OR}=1.9$ (95\% CI 1.1-3.4); low quality of life $\mathrm{OR}=3.4$ (95\% CI 2.6-4.6) and adjusted OR $=2.1$ (95\% CI 1.5-2.9).

Conclusion: Approximately 2 out of 10 older adults demonstrate frailty. This is associated with limitations in ADL, falls, and admission to emergency rooms during the previous year as well as low quality of life.

Keywords: frailty, aging, limitations in daily living, falls, emergency services, quality of life, social security

\section{Introduction}

Similar to other nations of the world, the Mexican population is aging, although this demographic trend in Mexico is occurring at a more rapid pace than in other countries. ${ }^{1}$ If the Mexican older adult population increased by $1.4 \%$ in the last 50 years (1950-2000), in the next 50 years (2000-2050) it will increase by 17.7\%. ${ }^{2}$ In Mexico City, in the year 2010 , the population reached 8,944,599 inhabitants, with 7.9\% (706,623 inhabitants) of older adults. It is expected that the older adult population in the next two decades will have a higher growth. In 2020, it is predicted that it will represent $10.8 \%$, and in 2030 , it will reach $14.7 \%$ of the total population. ${ }^{3}$ With a Mexican population aging at a rapid pace, there is a growing interest with regard to the study of frailty.

According to various studies worldwide, the prevalence of frailty in communitydwelling older adults ranges between $4.0 \%$ and $59.1 \%{ }^{4}$ This wide range of fluctuation in prevalence reported in the international literature is due to the different
Correspondence: Sergio Sánchez-García Unidad de Investigación Epidemiológica y en Servicios de Salud, Área

Envejecimiento, Instituto Mexicano del Seguro Social, Centro Médico Nacional Siglo XXI, Av. Cuauhtémoc No 330, Edificio CORCE, 3rd piso. Col Doctores, Delegación Cuauhtémoc, Ciudad de México, CP 06725, México Tel/fax +52 5556276900 ext 21846 Email sergio.sanchezga@imss.gob.mx 
diagnostic criteria used to determine frailty. A prevalence of frailty between $26.7 \%$ and $42.6 \%$ has been reported in Latin America. ${ }^{5}$ A prevalence of frailty between $14.1 \%$ and $39.5 \%$ has been reported in studies on the older adult Mexican population. ${ }^{5-8}$ A prevalence of $14.1 \%$ and $15.7 \%$ level of frailty in older adults living in the community has been reported in two studies in Mexico City, ${ }^{7,8}$ and it should be noted that these studies have included the entire population of older adults over the city.

Frailty can be defined as a state characterized by the progressive loss of reserve capacity and the lack of response to stressors. ${ }^{9}$ However, frailty remains an evolving concept, and there is no consensus in the diagnostic criteria used in clinical practice and epidemiological investigations, so different approaches in the literature have been reported. ${ }^{4,8,10-13}$

One of the most widely used approaches understands frailty as a syndrome characterized by the decline of age-related functional reserves or physiological systems, leading to the loss of homeostatic capacity to withstand stressors and resulting in a state of vulnerability. Fried et al describe the cycle of frailty and identified operational criteria for the frailty phenotype. ${ }^{9,14}$ Proposed criteria have been weight loss, self-report of exhaustion, low physical activity, slow ambulation, and weakness. It should be noted that in population-based studies, the frailty phenotype has been most frequently reported in the literature. ${ }^{13}$ The study of frailty is important from the social and public health perspective because it identifies groups of older adults who need additional medical care and are at increased adverse outcomes. ${ }^{15}$ Frailty makes individuals more vulnerable to adverse outcomes (disability, falls, hospitalization, and quality of life) through generally subtle and progressive physical changes. ${ }^{6,15,16}$ It is admitted that frailty, because of the related adverse outcomes, is costly for the patient and the society. ${ }^{15}$ The aim of this study is to determine the prevalence of frailty and its association with adverse outcomes in communitydwelling older adults in Mexico City.

\section{Methods}

A cross-sectional study was carried out from April to September 2014. The sample population was based on older adults ( $\geq 60$ years) who were beneficiaries of the Mexican Institute of Social Security (IMSS) in Mexico City. Data were derived from the database of the "Cohort of Obesity, Sarcopenia and Frailty of Older Mexican Adults" (COSFOMA). The research protocol was reviewed and approved by the National Committee of Scientific Investigation as well as by the Ethics Committee for Health Investigation (COMBIOETICA09CE101520130424) of the IMSS
(Registry Number: 2012-785-067). Written informed consent was obtained from all participants of the COSFOMA study.

Sample size was calculated under the assumption that $14.1 \%$ of community-dwelling older adults in Mexico City would present frailty, ${ }^{8}$ with an accuracy of the expected proportion of the phenomenon of $\pm 2 \%$ and a confidence level of $95 \%$. The minimum sample size was 1,164 older adults.

\section{Setting}

The IMSS is a mandatory social security system that offers a comprehensive package of benefits, including health care at all levels and economic benefits such as a retirement pension. IMSS-insured workers and their close relatives are affiliated to a Family Medicine Clinic based on their home address. The older adults who are insured by the IMSS are more likely to have $\leq 6$ years of education than their non-IMSS-affiliated counterparts. There are 48 Family Medicine Unit (FMU) located in Mexico City. The IMSS covers $36.5 \%$ of the population in Mexico City and $\sim 50.9 \%$ of older adults.

\section{Study population}

In 2013 the number of beneficiaries registered in FMU at IMSS Mexico City were 1,075,275. A random selection was done to obtain 10,000 records in order to locate addresses and telephone numbers. It was noted that $40.5 \%(n=4,054)$ of the records did not have a complete home address.

There were 5,946 letters sent to the addresses of the older adults to inform them of the nature of the study and invite them to participate, as well as to provide them with the address of the FMU, day and time when they should be present for the survey, and the corresponding clinical evaluation in case they wished to participate in the study. They were also provided with the telephone number where they could request further information and change their appointment or the FMU location, if they so desired.

\section{Data collection strategy}

Mexico City was geographically divided into eight quadrants for data collection. The FMU located in each of the quadrants was identified. The one with the best characteristics for accessibility and with the physical space for carrying out the survey and clinical evaluations was then identified for each quadrant. In cases in which the older adult did not attend the appointment, a phone call was made and, in some cases, a home visit.

Data collection was performed by healthcare professionals (previously trained and supervised by qualified research assistants) from April to September 2014 and was obtained via a questionnaire and evaluation scales to determine the 
sociodemographic characteristics (gender, age, marital status, education, employment, and living alone) as well as tobacco and alcohol consumption.

\section{Measurements}

Nutritional status was evaluated using body mass index (BMI): underweight was defined as $\mathrm{BMI} \leq 21.9$, normal weight BMI 22.0-29.9, and overweight BMI $\geq 30.0 .{ }^{17}$ Comorbidity was obtained with the report of chronic diseases diagnosed by a physician. Cognitive function was obtained through the Mini-mental Status Exam (MMSE): cognitive deterioration was considered with a cut-off point $\leq 23$ adjusted for education. ${ }^{18,19}$ Major depression was evaluated through the Center for Epidemiologic Studies Depression Scale-Revised (CESD-R). Major depression was considered when at least five symptoms were present, including dysphoria (depressed state) or anhedonia (inability to experience pleasure) for at least 2 weeks plus three of the following symptoms: significant weight change (appetite), sleep disorders, agitation or psychomotor delay, fatigue, excessive or inappropriate guilt, and suicidal ideation. ${ }^{20,21}$ Polypharmacy was considered to be the consumption of $\geq 5$ medications daily. ${ }^{7}$

\section{Assessment of frailty}

Operationalization of the phenotype of frailty was done using the five criteria proposed by Fried et al (Table 1). Frail adults are defined as those with three or more of the following criteria: self-report of weight loss, exhaustion, low physical activity, slowness, and weakness (low grip strength). The presence of one or two criteria indicates a pre-frail condition, whereas absence of criteria indicates a robust or nonfrail state. ${ }^{9}$

\section{Assessment adverse outcomes}

Adverse outcomes studied were limitation in basic activities of daily living (ADLs), falls and admission to emergency departments in the last year, and quality of life. A limitation in the ADL was considered when the older adult was unable to perform one or more of the following activities: bathing, dressing, using the bathroom, moving, continence, and feeding. ${ }^{22}$ The ocurrence of falls and admission to the emergency department in the last year was obtained with the record of one or more falls in the last year. The WHO Quality of Life Older Adults Scale (WHOQOL-OLD) was used to evaluate the relevant aspects of the quality of life of older adults. ${ }^{23}$ The score for the total score has a range of $0-100$. The low quartile (quartile 25) was used as the cut-off point to be considered as low quality of life.

\section{Statistical analysis}

IBM Statistical Package for Social Science (IBM-SPSS), v.23.0 for Windows, was used to calculate descriptive statistics and to obtain the frequency and percentage distributions. $\chi^{2}$ test was used to determine the homogeneity of the frequency and distribution of the sociodemographic characteristics (gender, age, marital status, education, employment, and living alone), tobacco consumption, alcohol consumption, nutritional status, comorbidity, cognitive function, depression, and polypharmacy ( $\geq 5$ medications) in relation with the phenotype of frailty as well as for adverse results (limitations in ADL, falls and admissions to

Table I Criteria for frailty phenotype

\begin{tabular}{|c|c|}
\hline Criterion & Operational definition \\
\hline Weight loss & $\begin{array}{l}\text { Differences between weight during the previous year and actual weight were calculated. Subjects with weight } \\
\text { loss }>10 \mathrm{lb}(4.5 \mathrm{~kg}) \text { during this period were classified as positive for the criterion of weight loss }\end{array}$ \\
\hline Self-report of & Two questions were used from the revised version of 35 items of the Center for Epidemiologic Studies Depression \\
\hline exhaustion & $\begin{array}{l}\text { Scale (CESD-R) adapted for older Mexican adults to determine the criteria of exhaustion. }{ }^{21,51} \text { Items considered were: } \\
\text { "I felt that everything I did was with difficulty" and "I could not continue." Considered positive for the criteria was if } \\
\text { the participant responded: "During 5-7 days in the past week" or "Almost every day for } 2 \text { weeks" }\end{array}$ \\
\hline Low physical activity & $\begin{array}{l}\text { Level of physical activity during the previous week was evaluated with the Physical Activity Scale for the Elderly } \\
\text { (PASE) questionnaire that included self-reported occupational, domestic, and recreational activities. }{ }^{52} \text { Low physical } \\
\text { activity was considered as } \leq 58.6 \text { points for men and } \leq 56.4 \text { points for women (low point quartile of PASE) }\end{array}$ \\
\hline Slowness & $\begin{array}{l}\text { Walking time was estimated for } 4.5 \mathrm{~m} \text { ( } 15 \mathrm{ft}) \text {, stratified by sex and stature. Walking distance was considered in } \\
\text { women with a height } \leq 159 \mathrm{~cm} \text {, time } \geq 7 \text { seconds and height }>159 \mathrm{~cm} \text {, time } \geq 6 \text { seconds. Walking distance was } \\
\text { considered in men with a height } \leq 173 \mathrm{~cm} \text {, time } \geq 7 \text { seconds and with a height }<173 \mathrm{~cm} \text {, time } \geq 6 \text { seconds }\end{array}$ \\
\hline Weakness (low grip & Grip strength of the nondominant hand was evaluated using dynamometry (Takei T.K.K500I, Takei Scientific \\
\hline strength) & 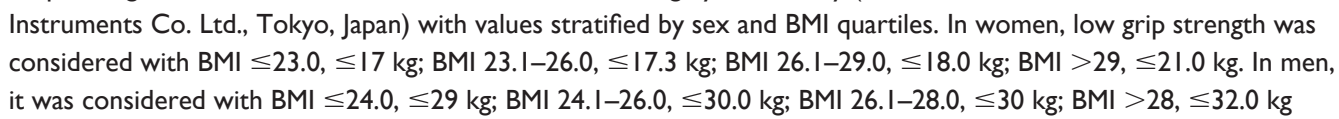 \\
\hline
\end{tabular}

Abbreviation: BMI, body mass index. 
the emergency services in the last year) in relation with the frailty phenotype (frail/pre-frail/not frail).

One-way analysis of variance (ANOVA) was used to determine any differences between the average of the score of the WHOQOL-OLD and the phenotype of frailty. Subsequently, Bonferroni post-hoc test was used to determine differences.

To determine the strength of association (odds ratio, OR) between frailty and adverse results (limitations in ADL, falls and admission to emergency services in the last year, and low quality of life), a bivariate logistic regression was used. Considered as a reference were older adults who presented $<3$ of the criteria proposed by Fried et al. ${ }^{9}$ The low quartile (quartile $25=59.4$ points) of the score from the WHOQOLOLD was used as the cut-off point to be considered as low quality of life. OR (95\% confidence interval [CI]) was then adjusted using the sociodemographic characteristics (tobacco consumption, alcohol consumption, nutritional status, comorbidity, cognitive function, depression, and polypharmacy).

\section{Results}

Of the 5,946 invitation letters sent, 1,547 older adults were contacted. A total of 4,399 older adults were not located for the following reasons: 57 were deceased, 290 moved, 638 did not live at the address, and for 3,414 subjects the address did not exist. Figure 1 describes the composition of

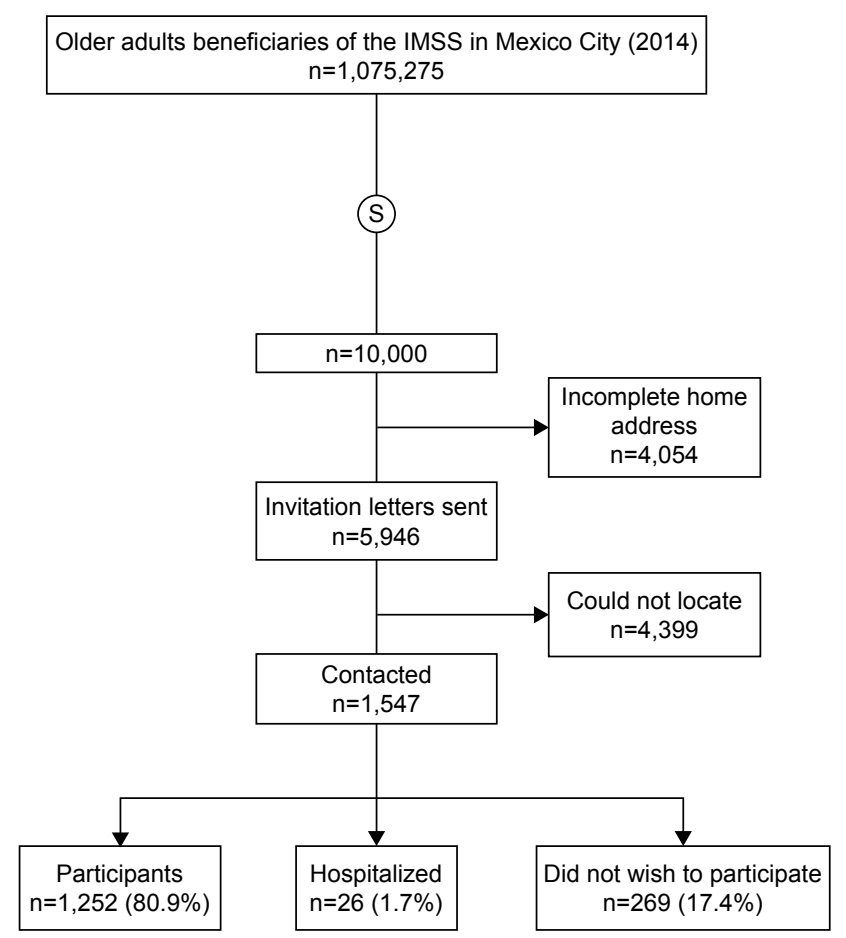

Figure I Composition of the sample of older adults beneficiaries of the IMSS in Mexico City.

Abbreviation: IMSS, Mexican Institute of Social Security. the sample of older adults who are beneficiaries of the IMSS from Mexico City.

Of the 1,547 older adults contacted, $80.9 \%(n=1,252)$ presented for the appointment, $1.7 \%(n=26)$ were hospitalized when their appointment was scheduled, and 17.4\% $(n=269)$ did not accept to participate in the study. The sample comprised of 1,252 older adults with a mean age of $68.5( \pm 7.2)$ years; $59.9 \%(n=750)$ were females and $40.1 \%(n=502)$ males with a mean age of 68.7 (7.4) years and 68.2 (6.8) years, respectively. Frequency and distribution of the characteristics of older adult beneficiaries of the IMSS from Mexico City who comprised the sample are shown in Table 2.

The frequency of the five criteria proposed by Fried et al for operationalization of the phenotype of frailty by sex is shown in Figure 2. The presence of weight loss in 1,252 older adults was $9.9 \%(n=124), 32.3 \%(n=405)$ with self-report of exhaustion, $25.8 \%(\mathrm{n}=323)$ with low physical activity, $25.2(n=315)$ with slow gait, and 59.7\% $(n=747)$ with low grip strength.

Frequency of the number of criteria was presented in the following manner: $21.8 \%(\mathrm{n}=273)$ did not present any criteria ( 0 criteria), $31.8 \%(n=398)$ one criterion, $25.8 \%(n=323)$ two criteria, $13.8 \%(n=173)$ three criteria, $5.9(n=74)$ four criteria, and $0.9 \%(n=11)$ five criteria. Frequency of the number of criteria proposed by Fried et al for operationalization of the phenotype of frailty by gender is shown in Figure 3.

The prevalence of frailty in older adults was $20.6 \%$ $(\mathrm{n}=258)$, pre-frail $57.6 \%(\mathrm{n}=721)$, and nonfrail $21.8 \%$ $(n=273)$. Frequency and distribution of the characteristics of older adult beneficiaries of the IMSS in Mexico City according to the phenotype of frailty are presented in Table 2. It was determined that there is no evidence of homogeneity in the frequency and distribution in relation to the phenotype of frailty according to sex, age, marital status, education, employment, alcohol consumption, nutritional status, comorbidity, cognitive function, depression, and polypharmacy $(P<0.050)$. There is no uniformity in the frequency and distribution in relation with the phenotype of frailty for living alone and tobacco consumption $(P>0.050)$.

Frequency and distribution of functional decline, falls, and admission to a hospital emergency room in the past year as well as the mean ( \pm standard deviation) total score of the WHOQOL-OLD in relation to the phenotype of frailty in older adults is presented in Table 3. There were $19.2 \%(n=240)$ of older adults with limitations in ADL; $26.8 \%(n=336)$ reported at least one fall in the previous year and $6.1 \%(n=76)$ used hospital emergency services. Mean of the total score of the WHOQOL-OLD was 68.5 $( \pm 12.8)$ points. 
Table 2 Characteristics of older adults in relation to the phenotype of frailty

\begin{tabular}{|c|c|c|c|c|c|}
\hline \multirow[t]{2}{*}{ Characteristics } & \multirow{2}{*}{$\frac{\text { All }}{\%(n)}$} & \multirow{2}{*}{$\frac{\text { Not frail }}{\%(n)}$} & \multirow{2}{*}{$\frac{\text { Pre-frail }}{\%(n)}$} & \multirow{2}{*}{$\frac{\text { Frail }}{\%(n)}$} & \multirow[t]{2}{*}{$P$-value ${ }^{\mathrm{a}}$} \\
\hline & & & & & \\
\hline Sex & & & & & $<0.001$ \\
\hline Women & $59.9(750)$ & $50.2(137)$ & 59.1 (426) & $72.5(187)$ & \\
\hline Men & $40.1(502)$ & $49.8(136)$ & $40.9(295)$ & $27.5(71)$ & \\
\hline Age (years) & & & & & $<0.001$ \\
\hline$>80$ & 9.5 (119) & I.8 (5) & $7.7(55)$ & $22.8(59)$ & \\
\hline $70-79$ & $26.5(332)$ & $19.8(54)$ & $25.9(187)$ & $35.3(91)$ & \\
\hline $60-69$ & $64.0(801)$ & $78.4(2 \mid 4)$ & 66.4 (479) & $41.9(108)$ & \\
\hline Marital status & & & & & $<0.001$ \\
\hline Widow & $19.7(247)$ & $12.8(35)$ & $19.0(137)$ & 29.1 (75) & \\
\hline Single & $20.9(261)$ & $16.5(45)$ & $21.5(155)$ & $23.6(61)$ & \\
\hline Married/free union & $59.4(744)$ & 70.7 (193) & 59.5 (429) & $47.3(122)$ & \\
\hline Education & & & & & $<0.001$ \\
\hline None & $4.1(5 \mathrm{I})$ & $2.2(6)$ & $2.9(21)$ & $9.3(24)$ & \\
\hline $1-6$ years & $32.6(409)$ & $19.4(53)$ & 31.5 (227) & $50.0(129)$ & \\
\hline$\geq 7$ years & $63.3(792)$ & $78.4(2 \mid 4)$ & $65.6(473)$ & $40.7(105)$ & \\
\hline Paid employment & & & & & $<0.001$ \\
\hline Yes & 35.1 (439) & 44.7 (I22) & $34.7(250)$ & $26.0(67)$ & \\
\hline No & $64.9(8 \mid 3)$ & $55.3(|5|)$ & $65.3(47 I)$ & $74.0(191)$ & \\
\hline Live alone & & & & & 0.292 \\
\hline Yes & $10.1(126)$ & $9.5(26)$ & II.I (80) & $7.8(20)$ & \\
\hline No & $89.9(1,126)$ & $90.5(247)$ & $88.9(64 I)$ & $92.2(238)$ & \\
\hline Tobacco use & & & & & 0.558 \\
\hline Yes & $9.3(117)$ & II.0 (30) & $9.0(65)$ & $8.5(22)$ & \\
\hline No & $90.7(1,135)$ & $89.0(243)$ & $91.0(656)$ & $91.5(236)$ & \\
\hline Alcohol consumption & & & & & 0.002 \\
\hline Yes & $24.8(311)$ & $29.3(80)$ & $26.1(188)$ & $16.7(43)$ & \\
\hline No & $75.2(94 I)$ & $70.7(193)$ & $73.9(533)$ & $83.3(215)$ & \\
\hline Nutritional status & & & & & 0.007 \\
\hline Overweight/obesity $(\geq 30)$ & $28.8(36 I)$ & $26.7(73)$ & $26.5(191)$ & $37.6(97)$ & \\
\hline Underweight $(\leq 21.9)$ & $9.8(123)$ & $8.1(22)$ & $10.8(78)$ & $8.9(23)$ & \\
\hline Normal weight (22.0-29.9) & $61.4(768)$ & $65.2(178)$ & $62.7(452)$ & $53.5(138)$ & \\
\hline Comorbidity & & & & & $<0.001$ \\
\hline$\geq 3$ & $4.7(58)$ & $4.4(12)$ & $3.5(25)$ & $8.1(2 I)$ & \\
\hline $1-2$ & $33.5(420)$ & $27.1(74)$ & $34.0(245)$ & $39.2(101)$ & \\
\hline 0 & $61.8(774)$ & $68.5(187)$ & $62.6(45 I)$ & $52.7(136)$ & \\
\hline Cognitive decline & & & & & $<0.001$ \\
\hline Yes & $24.3(304)$ & II.7 (32) & $22.5(162)$ & $42.6(110)$ & \\
\hline No & 75.7 (948) & $88.3(24 I)$ & 77.5 (559) & $57.4(148)$ & \\
\hline Depression & & & & & $<0.001$ \\
\hline Yes & $4.2(53)$ & $0.0(0)$ & $2.6(19)$ & $13.2(34)$ & \\
\hline No & $95.8(1,199)$ & $100(273)$ & $97.4(702)$ & $86.8(224)$ & \\
\hline Polypharmacy & & & & & $<0.029$ \\
\hline Yes & $23.2(291)$ & $22.0(60)$ & $21.5(155)$ & $29.5(76)$ & \\
\hline No & $76.8(96 I)$ & $78.0(2 \mid 3)$ & $78.5(566)$ & 70.5 (182) & \\
\hline
\end{tabular}

Note: ${ }^{\mathrm{a}} \chi^{2}$ test.

Significant differences were shown in the frequency and distribution in relation with the phenotype of frailty and adverse results, in limitations in ADL, in falls in the last year, and in admission to a hospital emergency department in the last year $(P<0.050)$. A difference was also observed between the mean of the total score of the WHOQOL-OLD in relation with the phenotype of frailty $(P<0.050)$. Bonferroni post-hoc test identified that the difference between the means was found among all groups $(P \leq 0.001)$.

The association between frailty and the presence of limitations in ADL in older adults was OR $=2.3,95 \%$ CI 1.7-3.2, falls in the last year OR $=1.6,95 \%$ CI $1.2-2.1$, admission to emergency service in the last year $\mathrm{OR}=1.9$, 95\% CI 1.1-3.1, and for low quality of life was OR $=3.4$, 95\% CI 2.6-4.6. The strength of association adjusted in older 


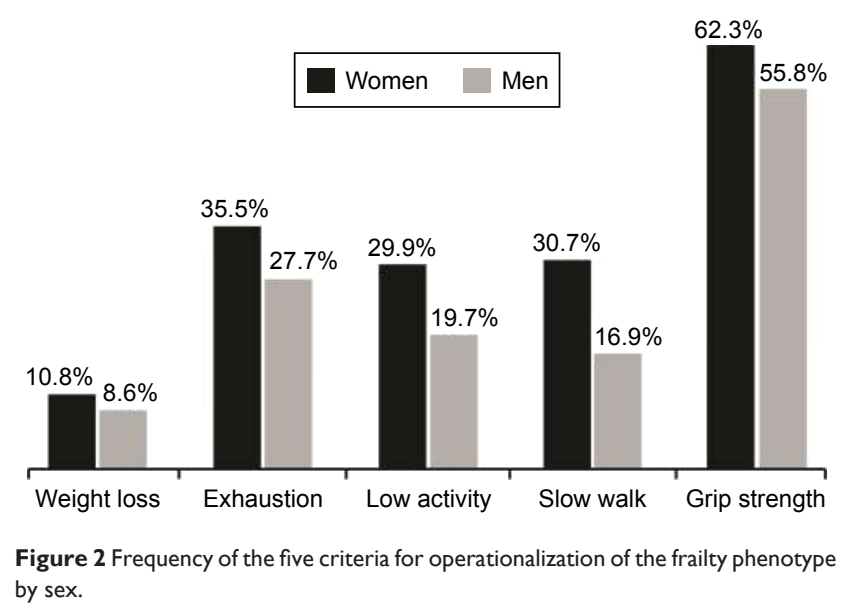

adults with limitations in ADL was adjusted $\mathrm{OR}=1.7,95 \%$ CI 1.2-2.4, falls in the last year adjusted OR $=1.4,95 \% \mathrm{CI}$ 1.0-1.9, admission to hospital emergency services in the last year adjusted $\mathrm{OR}=1.9,95 \% \mathrm{CI} 1.1-3.4$, and for low quality of life adjusted OR $=2.1,95 \%$ CI 1.5-2.9.

\section{Discussion}

The prevalence of frailty in this study was $20.6 \%$ in a sample of 1,252 subjects, that is, $\sim 2$ out of 10 older adults exhibit frailty. As mentioned previously, the prevalence of frailty reported internationally in community-dwelling older adults varies between $4.0 \%$ and $59.1 \%,{ }^{4}$ with the presence of frailty in older adults of Mexico City ranked at an intermediate level.

In population-based cross-sectional studies carried out previously in Mexico City, a prevalence of $14.1 \%$ was reported in a sample of 1,124 older adults, ${ }^{6} 15.7 \%$ in a sample of 1,933 older adults, ${ }^{13}$ and $39.5 \%$ in a sample of 1,311 older adults. ${ }^{8}$ It should be noted that among these studies, only the first has a sample population based in Mexico City. ${ }^{6}$ The other two studies are representative of $1 / 16$ districts $^{8}$ or of $14 / 16$ districts existing in Mexico City. ${ }^{13}$

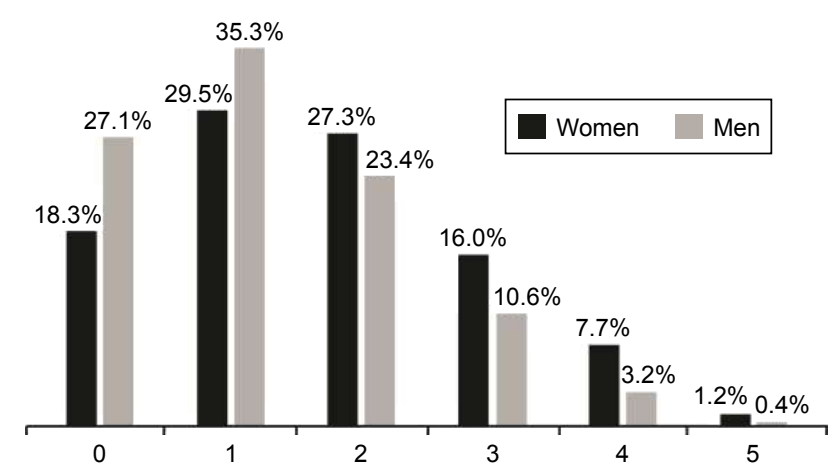

Figure 3 Frequency of the number of criteria for operationalization of the frailty phenotype by sex.
Similarly, operationalization of the frailty phenotype has been proposed differently, which does not allow for a comparison. However, it has allowed us to obtain an idea of the percentage of the population requiring additional medical care to prevent adverse results. ${ }^{21}$ Taking into consideration that frail older adults become major consumers of health services, their costs of medical and hospital care are higher proportionally to the rest of the population..$^{14,15,17,18}$

Frailty is a concept used in clinical practice and epidemiological investigation for more than two decades. ${ }^{5,-11,13,14,17,24-26}$ This concept of frailty has been born as a condition associated with a higher risk of functional decline among persons of advanced age, which could be independent of the presence of comorbidities and of aging. ${ }^{9-11,27-29}$ Our results show an association between frailty and the presence of limitations in one or more ADL. Functional decline has been considered to be a state of pre-disability (a "physiological precursor" and "etiological factor" in disability) and represents a potentially useful tool for the initial risk stratification in older adults and for preventive interventions. ${ }^{27}$

Our results show an association between frailty and presence of falls in adults studied in the last year. This could be due to the weakness and low resistance displayed by older adults with this disorder. It has been demonstrated that frailty is an important predictor for future falls among older community-dwelling adults even though the fact that the criteria used to define frailty have been different in other studies. ${ }^{30}$ Although frailty is a phenotype distinct from disability, frailty begins by affecting mobility before clinically important outcomes such as falls occur. Therefore, the beginning of frailty is the optimum time for carrying out interventions aimed at preventing disability in mobility, thus avoiding future falls. ${ }^{31}$

An association exists between frailty and admission to emergency services in the previous year. This is due to the condition of frailty and the cumulative effect of multiple exposures as well as the physical, psychological, and social conditions commonly unfavorable in older adults, with a higher disease load that increases the use of medical and hospital services. ${ }^{24-26,32,33} \mathrm{~A}$ fundamental challenge of health policies falls on the decision of implementing services oriented toward aging or redirecting usual services toward the needs of older adults as a high-risk population for presenting frailty. This is an essential decision especially when health systems of developing countries are facing not only the palpable challenges of aging and the epidemiological transition, but also parallel to basic and acute health problems related with poverty in a large sector of the population. ${ }^{34,35}$ 
Table 3 Adverse outcomes in relation to the phenotype of fraility in older adults

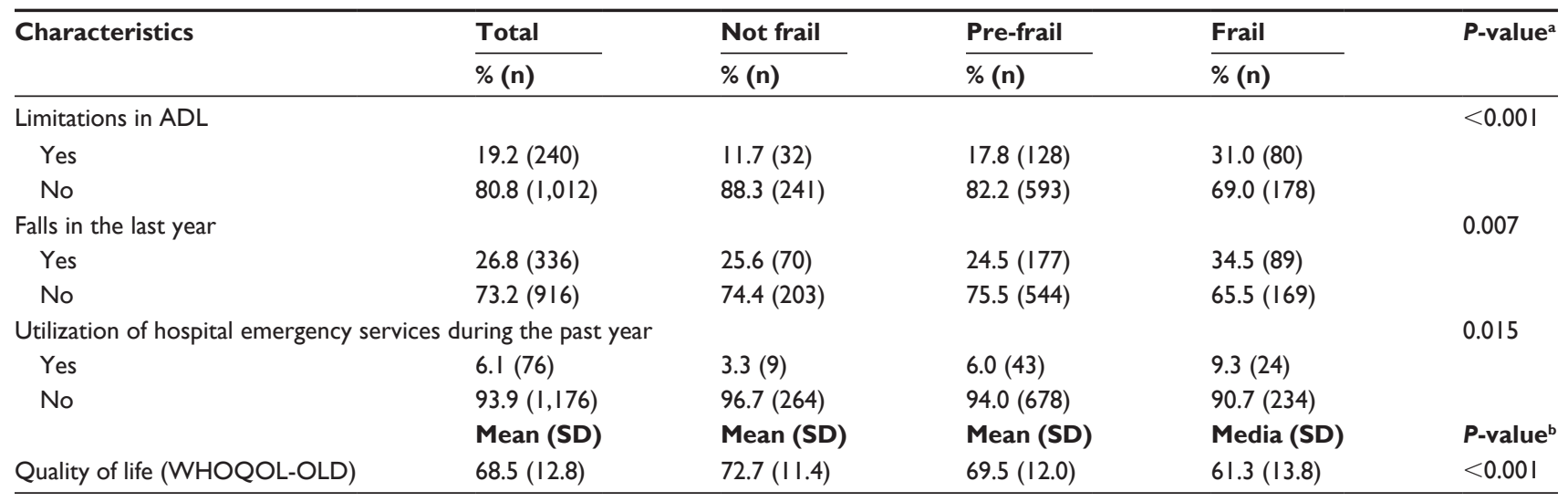

Notes: ${ }^{a} \chi^{2}$ test. ${ }^{b}$ ANOVA (one-way analysis of variance).

Abbreviations: SD, standard deviation; ADL, activities of daily living; WHOQOL-OLD, WHO Quality of Life Older Adults Scale.

Therefore, the study of frailty is fundamental for developing countries for the implementation of policies and programs designed to prevent frailty in early ages and, when frailty is present, to minimize the risk of adverse outcomes in older adults.

Quality of life of the older adults is closely related to functional capacity and the set of conditions that allow maintaining their participation in self-care, socialization, and family life by restructuring their lives around their capabilities and limitations, learning to enjoy older age, and living life to the fullest. In recent decades, frailty and quality of life have been widely studied in older adults without having consensus definitions; however, this is generally recognized as a result of the interaction of multiple systems and/or domains. ${ }^{10,36,37}$ Consequences of this interaction vary among individuals with similar health problems as well as with the same individual. ${ }^{36,37}$ Previous studies have documented that there may be cultural differences in the conception of quality of life. ${ }^{38,39}$

In our study it was determined that frailty is associated in older adults with a low quality of life. The instrument used to determine quality of life (WHOQOL-OLD) is an alternative to the WHOQOL-100 or WHOQOL-BREF used to carry out research on quality of life in older adults. ${ }^{40}$ The WHOQOLOLD advantage is that it evaluates relevant aspects of the quality of life of older adults. ${ }^{23,40}$ Our results are consistent with studies from other countries that have reported that frail older adults have a low quality of life. ${ }^{16,15,41}$ Research on frailty in different countries is recommended to determine to what extent contextual characteristics influence the adverse outcomes in older adults. ${ }^{42}$

We present the prevalence of frailty and its association with adverse outcomes in a sample community-dwelling older adult insured by the largest health care provider in Mexico City. Results, however, must be interpreted in light of several limitations. An evident limitation of this study is that we were only able to interview a low fraction of the selected older adults, mainly as a result of a lack of active update in the insured census used to identify study participants. We are aware that nonparticipation in this study has the potential to introduce bias into the results. ${ }^{43}$ This bias refers to the systematic errors introduced in the study, as per the inability to study additional candidates due to location and those did not wish to participate in the study. However, different studies have found little evidence for substantial bias as a result of nonparticipation..$^{44,45}$ and response rates of our study are consistent with similar studies. ${ }^{44,46-49}$

Other limitation of this study is its cross-sectional design for establishing association between frailty and adverse outcomes in older adults. Also in this study, it was impossible to analyze adverse outcomes simultaneously. It may be possible that an adverse outcome could be preceded by another adverse effect. Nevertheless, we have to consider that frailty is a result of various chronic events and deficits that add up over the life span, although it may be reversible. Although we could not analyze temporality, we show that people who present frailty at one point have a greater probability of presenting additional adverse outcomes in a period close to which frailty identified. ${ }^{14,15,50}$ In order to overcome this limitation, it is necessary to carry out longitudinal studies to establish the causal link between frailty and adverse outcomes on the community-dwelling population of older adults.

\section{Conclusion}

Approximately 2 out of every 10 older adults present frailty associated with limitations in ADL, falls and admission to 
emergency services in the prior year, and a low quality of life. It is necessary to investigate the effectiveness and viability of implementing measures designed to prevent frailty and to minimize risks of adverse outcomes in older adults.

\section{Acknowledgments}

The authors wish to thank the older adults participating in this study as well as the authorities and staff of the South and North Delegations of the Mexican Institute of Social Security (IMSS) of Mexico City for supporting this study, and the Thematic Investigations Network for Aging, Health and Social Development, CONACyT. This study was funded by grants from Health Research and Social Security Sector Fund SS/IMSS/ISSSTE/CONACyT (SALUD-2013-01201112) and the Fund for the Promotion of Health Research (FIS/IMSS/PROT/PRIO/13/024), IMSS. Data are available upon request.

\section{Author contributions}

All authors contributed toward data analysis, drafting and revising the paper and agree to be accountable for all aspects of the work.

\section{Disclosure}

The authors report no conflicts of interest in this work.

\section{References}

1. World Bank. Policy Research Report. Averting the Old Age Crisis Policies to Project the Old and Promote Growth. Washington, DC: Oxford University Press; 1994.

2. Consejo Nacional de Población (CONAPO). Proyecciones de Población 2000-2050. Distrito Federal, México: CONAPO; 2002.

3. Consejo Nacional de Población (CONAPO). Dinámica demográfica 1990-2010 y proyecciones de población 2010-2030. Distrito Federal, México: CONAPO; 2014.

4. Collard RM, Boter H, Schoevers RA, Oude Voshaar RC. Prevalence of frailty in community-dwelling older persons: a systematic review. J Am Geriatr Soc. 2012;60(8):1487-1492.

5. Alvarado BE, Zunzunegui MV, Béland F, Bamvita JM. Life course social and health conditions linked to frailty in Latin American older men and women. J Gerontol A Biol Sci Med Sci. 2008;63(12):1399-1406.

6. Díaz de León González E, Tamez Pérez HE, Gutiérrez Hermosillo H, Cedillo Rodríguez JA, Torres G. Frailty and its association with mortality, hospitalization and functional dependence in Mexicans aged 60-years or older. Med Clin (Barc). 2012;138(11):468-474.

7. Gnjidic D, Hilmer SN, Blyth FM, et al. High-risk prescribing and incidence of frailty among older community-dwelling men. Clin Pharmacol Ther. 2012;91(3):521-588.

8. Sánchez-García S, Sánchez-Arenas R, García-Peña C, et al. Frailty among community-dwelling elderly Mexican people: prevalence and association with sociodemographic characteristics, health state and the use of health services. Geriatr Gerontol Int. 2014;14(2):395-402.

9. Fried LP, Tangen CM, Walston J, et al. Frailty in older adults: evidence for a phenotype. J Gerontol Med Sci. 2001;56(3):M146-M156.

10. Bortz WM. A conceptual framework of frailty: a review. J Gerontol Med Sci. 2002;57(5):M283-M288.
11. Sternberg SA, Wershof Schwartz A, Karunananthan S, Bergman H, Mark Clarfield A. The identification of frailty: a systematic literature review. J Am Geriatr Soc. 2011;59(11):2129-2138.

12. Xue QL. The frailty syndrome: definition and natural history. Clin Geriatr Med. 2011;27(1):1-15.

13. Bouillon K, Kivimaki M, Hamer M, et al. Measures of frailty in population-based studies: an overview. BMC Geriatr. 2013;21:64.

14. Fried LP, Walston J. Frailty and failure to thrive. In: Hazzard W, Blass J, Ettinger WH, Halter J, Ouslander J, editors. Principles of Geriatric Medicine and Gerontology. New York: McGraw-Hill Professional; 1999.

15. Buckinx F, Rolland Y, Reginster JY, Ricour C, Petermans J, Bruyère O. Burden of frailty in the elderly population: perspectives for a public health challenge. Arch Public Health. 2015;73(1):19.

16. Masel MC, Ostir GV, Ottenbacher KJ. Frailty, mortality, and healthrelated quality of life in older Mexican Americans. J Am Geriatr Soc. 2010;58(11):2149-2153.

17. Douketis JD, Paradis G, Keller H, Martineau C. Overweight and obesity: Canadian guidelines for body weight classification in adults: application in clinical practice to screen for overweight and obesity and to assess disease risk. Can Med Assoc J. 2005;172(8):995-998.

18. Folstein MF, Folstein SE, McHugh PR. "Mini-mental state". A practical method for grading the cognitive state of patients for the clinician. J Psychiatr Res. 1975;12(3):189-198.

19. Beaman SR, Beaman PE, Garcia-Peña $C$, et al. Validation of a modified version of the Minimental State Examination (MMSE) in Spanish. Aging Neuropsychol Cognition. 2004;11:1-11.

20. Eaton W, Muntaner C, Smith C. Revision of the Center for Epidemiologic Studies Depression (CES-D) Scale. Baltimore: Johns Hopkins University Prevention Center; 1998.

21. Sánchez-García S, Juárez-Cedillo T, Gallegos-Carrillo K, Gallo JJ, Wagner FA, García-Peña C. Frecuencia de los síntomas depresivos entre adultos mayores de la Ciudad de México. Salud Ment. 2012;35(1): 71-77.

22. Katz S, Ford AB, Moskowitz RW, et al. Studies of illness in the aged. The index of ADL: a standardized measure of biological and psychosocial function. JAMA. 1963;185:914-919.

23. Lucas-Carrasco R, Laidlaw K, Power MJ. Suitability of the WHOQOLBREF and WHOQOL-OLD for Spanish older adults. Aging Ment Health. 2011;15(5):595-604.

24. De Jonge KE, Jamshed N, Gilden D, Kubisiak J, Bruce SR, Taler G. Effects of home-based primary care on Medicare costs in high-risk elders. J Am Geriatr Soc. 2014;62(10):1825-1831.

25. Mohandas A, Reifsnyder J, Jacobs M, Fox T. Current and future directions in frailty research. Popul Health Manag. 2011;14(6): 277-283.

26. Robinson TN, Wu DS, Stiegmann GV, Moss M. Frailty predicts increased hospital and six-month healthcare cost following colorectal surgery in older adults. Am J Surg. 2011;202(5):511-514.

27. Clegg A, Young J, Iliffe S, Rikkert MO, Rockwood K. Frailty in elderly people. Lancet. 2013;381(9868):752-762.

28. Morley JE, Vellas B, van Kan GA, et al. Frailty consensus: a call to action. J Am Med Dir Assoc. 2013;14(6):392-397.

29. Woodhouse KW, Wynne H, Baillie S, James OFW, Rawlins MD. Who are the frail elderly? Q J Med. 1988;68(255):505-506.

30. Kojima G. Frailty as a predictor of future falls among communitydwelling older people: a systematic review and meta-analysis. $J \mathrm{Am}$ Med Dir Assoc. 2015;16(12):1027-1033.

31. McAdams-DeMarco MA, Suresh S, Law A, et al. Frailty and falls among adult patients undergoing chronic hemodialysis: a prospective cohort study. BMC Nephrol. 2013;14:224.

32. Lutomski JE, Baars MA, Boter H, et al. Frailty, disability and multimorbidity: the relationship with quality of life and healthcare costs in elderly people. Ned Tijdschr Geneeskd. 2014;158:A7297.

33. González-González C, Sánchez-García S, Juárez-Cedillo T, RosasCarrasco O, Gutiérrez-Robledo LM, García-Peña C. Health care utilization in the elderly Mexican population: expenditures and determinants. BMC Public Health. 2011;11:192. 
34. Sánchez-Garcia S, Juárez-Cedillo T, Espinel-Bermudez C, CárdenasBahena A, García-Peña C. Health status and wellness among older adult beneficiaries of the ISSSTE and IMSS in Southwest Mexico City. Rev Invest Clin. 2013;65(2):165-173.

35. Martin LG, Kinsella K. Research on the demography of aging in developing countries. In: Martin LG, Preston SH, editors. Demography of Aging. Washington, DC: National Academy Press; 1994.

36. Carr A, Gibson B, Robinson P. Measuring quality of life: is quality of life determined by expectations or experience? Br Med J. 2001;322(7296): 1240-1243.

37. Markle-Reid M, Browne G. Conceptualizations of frailty in relation to older adults. J Adv Nurs. 2003;44(1):58-68.

38. Buck D, Jacoby A, Baker GA, Ley H, Steen N. Cross-cultural differences in health-related quality of life of people with epilepsy: findings from a European study. Qual Life Res. 1998;8(8):675-685.

39. Kang Y. Gender and culture differences in the quality of life among Americans and Koreans with atrial fibrillation. Nurs Health Sci. 2009; 11(3):301-305.

40. Power M, Quinn K, Schmidt S; WHOQoL-OLD group. Development of the WHOQOL-Old module. Qual Life Res. 2005;14(10):2197-2214.

41. Mulasso A, Roppolo M, Rabaglietti E. The role of individual characteristics and physical frailty on health related quality of life (HRQOL): a cross sectional study of Italian community-dwelling older adults. Arch Gerontol Geriatr. 2014;59(3):542-548.

42. Olaroiu M, Ghinescu M, Naumov V, Brinza I, van den Heuvel W Does frailty predict health care utilization in community-living older Romanians? Curr Gerontol Geriatr Res. 2016;2016:6851768.

43. Jacomb PA, Jorm AF, Korten AE, Christensen H, Henderson AS. Predictors of refusal to participate: a longitudinal health survey of the elderly in Australia. BMC Public Health. 2002;2:4.

44. Galea S, Tracy M. Participation rates in epidemiologic studies. Ann Epidemiol. 2007;17(9):643-653.
45. Shahar E, Folsom AR, Jackson R. The effect of nonresponse on prevalence estimates for a referent population: insights from a populationbased cohort study. Atherosclerosis Risk in Communities (ARIC) Study Investigators. Ann Epidemiol. 1996;6(6):498-506.

46. Oris M, Guichard E, Nicolet M, et al. Representation of vulnerability and the elderly. A total survey error perspective on the VLV survey. In: Oris M, Roberts C, Joye D, Ernst Stähli M, editors. Surveying Human Vulnerabilities across the Life Course. Cham: Springer International Publishing; 2016.

47. Romero LJ, Lindeman RD, Hundley R, et al. Outcome of recruitment and report on participation rate in the New Mexico Elder Health Survey. Ethn Dis. 1998;8(8):350-359.

48. García-Peña C, Wagner FA, Sánchez-Garcia S, et al. Depressive symptoms among older adults in Mexico City. J Gen Intern Med. 2008; 23(12):1973-1980.

49. Lien RK, Schillo BA, Goto CJ, Porter L. The effect of survey nonresponse on quitline abstinence rates: implications for practice. Nicotine Tob Res. 2016;18(1):98-101.

50. de Vries NM, Staal JB, van Ravensberg CD, Hobbelen JS, Olde Rikkert MG, Nijhuis-van der Sanden MW. Outcome instruments to measure frailty: a systematic review. Ageing Res Rev. 2011;10(1): 104-114.

51. Sánchez-García S, Juárez-Cedillo T, García-González JJ, et al. Usefulness of two instruments in assessing depression among elderly Mexicans: in population studies and for primary care. Salud Publica Mex. 2008;50(6):447-456.

52. Washburn RA, McAuley E, Katula J, Mihalko SL, Boileau RA. The physical activity scale for the elderly (PASE): evidence for validity. $J$ Clin Epidemiol. 1999;52(7):643-651.
Clinical Interventions in Aging

\section{Publish your work in this journal}

Clinical Interventions in Aging is an international, peer-reviewed journal focusing on evidence-based reports on the value or lack thereof of treatments intended to prevent or delay the onset of maladaptive correlates of aging in human beings. This journal is indexed on PubMed Central, MedLine,

\section{Dovepress}

CAS, Scopus and the Elsevier Bibliographic databases. The manuscript management system is completely online and includes a very quick and fair peer-review system, which is all easy to use. Visit http://www.dovepress. com/testimonials.php to read real quotes from published authors. 